\title{
A EVOLUÇÃO DO CONCEITO DE EXPERIÊNCIA NA EDUCAÇÃO
}

\author{
THE EVOLUTION ON THE CONCEPT OF EXPERIENCE ON EDUCATION
}

\author{
Daniel Bramo Nascimento de Carvalho ${ }^{1}$ \\ Mildon Carlos Calixto ${ }^{2}$ \\ Advanusia Santos Silva de Oliveira ${ }^{3}$ \\ Ester Fraga Vilas-Bôas Carvalho do Nascimento ${ }^{4}$
}

RESUMO: O presente texto tem como objetivo tratar da evolução do conceito de experiência entre os séculos XVI e XX da era cristã. Para isso, debruçou-se nas reflexões de Desiderus (1996), Dewey (1978), Locke (1983), Rousseau (2004), Spencer (s/d) e Verney (1952). Assim, apresentamos distintos diálogos no entorno do conceito experiência na tentativa exaustiva de estabelecer uma análise acurada deste tema complexo que move a dinâmica da respectiva pesquisa. O que interessou foi observar a trajetória do conceito em diferentes ideias e objetos de estudos, onde a experiência tomava forma enquanto conceito importante nas práticas de educação do homem. Portanto, concluímos que o conceito ocupou bastantes espaços entre as reflexões e objetos de estudos dos pensadores filosóficos e da educação, demonstrando, assim, que compreender a experiência é compreender um

\footnotetext{
${ }^{I}$ Doutorando em Educação pela Universidade Tiradentes de Sergipe (PPED/UNIT). Mestre em Educação pelo PPED e Licenciado em História pela Universidade Tiradentes. Membro e pesquisador do Grupo de Estudo Comunicação, Educação e Sociedade. (GECES). E-mail: historiadobramo@gmail.com. Lattes: http://lattes.cnpq.br/ 7736202864956920. Orcid https://orcid.org/oooo-ooor-8491-3875.

2 Doutorando em Educação pela Universidade Tiradentes de Sergipe (PPED/UNIT). Mestre em educação pela Universidade Tiradentes de Sergipe. Professor de nível superior. E-mail: mildoneduc@gmail.com. Lattes: http://lattes.cnpq.br/ 9886255471607.

${ }_{3}^{3}$ Doutorando em Educação pela Universidade Tiradentes de Sergipe (PPED/UNIT). Mestre em Educação pela Universidade Federal de Sergipe. Professora da Rede pública Municipal de Aracaju. Licenciada em Pedagogia e Letras Português e Espanhol. Membro do Grupo de Pesquisa Docência, Avaliação, Currículo e Contemporaneidade - GPDACC/CNPq/UNIT. Lattes:http://lattes.cnpq.br/973986771334685o. Orcid: https://orcid.org/oooo-ooo3-2654-8683.

4 Doutora em História da Educação pelo Programa de Estudos Pós-Graduados em Educação: História, Política, Sociedade da PUC de São Paulo. Mestre em Educação pelo Núcleo de Pós-Graduação em Educação da Universidade Federal de Sergipe. Bolsista de Produtividade em Educação pelo CNPq, desde 2012. Professora do Programa de Pós-Graduação em Educação da Unit, coordenando no período de 2006 a 2013. Pró-Reitora de Pós-Graduação, Pesquisa e Extensão da mesma instituição, no período de 2011 a 2015.Membro da Academia Sergipana de Letras, da Academia Sergipana de Educação, da Academia Brasileira Rotária de Letras/SE, da Academia Brasileira Teológica de Letras/SE, da Sociedade Bíblica do Brasil/SE, da Sociedade Brasileira de História da Educação. Lidera o Grupo de Pesquisa História das Práticas Educacionais/CNPq/UNIT. E-mail: esterfraga@gmail.com. Lattes: http://lattes.cnpq.br/5387293048319734 Orcid: https://orcid.org/oooo-oooz-4050-767X.
} 
pouco dos métodos educacionais que eram aplicados em diferentes séculos da história do homem.

Palavras-chave: Ato Educativo. Conceito. Educação. Experiência.

ABSTRACT: The aim of this text is to detain the evolution on the concept of experience between the $16^{\text {th }}$ and $20^{\text {th }}$ centuries on the Christian Era. To achieve this goal, the reflections of Desiderus (1996), Dewey (1978), Locke (1983), Rosseu (2004), Spencer (n.d.) and Verney (1952) were used. Hence, different dialogues were exposed around the concept of experience on the exhausting trying of establishing an accurate analysis of this complex theme that moves the dynamic of the respective research. The interest comes from observing the trajectory in divergent ideas and purpose of studies, where the experience was shaped as an important concept on practices of man education. In conclusion, the concept occupied a great extention between reflections and study goals of philosophers and educational thinkers, demonstrating, therefore, that understanding the experience is understand little more about educational methods that were applied in centuries of human history.

Keywords: Educational Act. Concept. Education. Experience.

\section{INTRODUÇÃO}

No decorrer da pesquisa aprofundamos ideias de caráter preliminares, mas que trazem informações significativas os quais serão discutidas no desdobramento do trabalho em curso. Metodologicamente a investigação apresenta como abordagem uma visão sistemática dialética na perspectiva experimental pelo viés reflexivo, por meio de uma ação pedagógica embasada em interface bibliográfico.

"Educar-se é crescer, não já no sentido puramente fisiológico, mas no sentido espiritual, no sentido humano, no sentido de uma vida cada vez mais larga, mais rica e mais bela, em um mundo cada vez mais adaptado, mais propício, mais benfazejo para o homem". (DEWEY, 1978, p. 17). Este artigo, que tem como tema "A evolução do conceito de experiência na educação”, é inspirado nas discussões da disciplina Teorias Educacionais, as quais incluem autores consagrados nos temas ligados às experiências na educação e conceitos transformadores na formação/educação.

As análises aqui apresentadas são baseadas nas reflexões dos livros De Civilitate Morum Puerilium, de Erasmo Desiderius (1996); Vida e Educação, escrito de John Dewey (1978); Ensaio acerca do entendimento humano, de John Locke (1983); Didáctica Magna, de 
Johann Amos Comenius (2006); A Educação do Homem, de Friedrich Froebel (200I); Carta Sobre Educação Infantil, de Johann Heinrich Pestalozzi (200o); Emílio ou Da Educação, escrito por Jean-Jacques Rousseau (2004); Educação intelectual, moral e physica, de Herbert Spencer (s/d); e Verdadeiro método de estudar, de Luiz Antônio Verney (1952).

As nove obras apresentam reflexões sobre o objeto de estudo deste trabalho, isto é, a evolução do conceito de experiência na educação do indivíduo e sua relação com a construção do conhecimento do homem.

Este trabalho tem como objetivo geral discutir os conceitos de experiências e suas evoluções em consonância com a prática de educação do homem nos séculos supracitados. Além disso, pretende-se especificamente, ressaltar a relevância da mesma efetiva na educação e compreender quais definições são debatidas e reveladas sobre o processo educativo na experiência a partir dos conceitos experiências e suas relações com a prática de educação do homem com base nos autores acima citados.

Mediante o exposto, segue o problema de pesquisa: Como vem manifestando-se a experiência do indivíduo na incidência de sua relação na educação ao longo dos anos? A fim de responder o problema, elegeram-se os seguintes pressupostos: Quais as manifestações das experiências do indivíduo sobre sua relação no seu processo educativo enquanto sujeito da sua realidade. Quais conceitos debatidos e revelados sobre o processo educativo da experiência?

Logo, este artigo se justifica pela análise e difusão da relevância relacionada ao objeto de estudo, com implicações ao refletir sobre a relação da experiência com o processo educativo do homem no pensar a educação ao longo dos séculos.

O conceito de experiência, de John Dewey (1978, p. 14), abrange, de forma precisa, as características da "relação que se processa entre dois elementos do cosmos, alterandolhes, até certo ponto, a realidade”. Portanto, para este autor, a educação é "o processo de reconstrução e reorganização da experiência, pelo qual lhe percebemos mais agudamente o sentido, e com isso nos habilitamos a melhor dirigir o curso de nossas experiências futuras”. (DEWEY, 1978, p. 17). 
É importante deixar claro que não se propõe, aqui, construir uma comparação entre os conceitos de experiência que são estabelecidos pelos autores, uma vez que o objetivo é discutir os conceitos de experiências e suas relações com a prática de educação do homem nos séculos XVI a XX.

Sendo assim, o viés educativo do homem envolve um processo ativo de assimilação orgânica, iniciado internamente, relacionando o pressuposto que o indivíduo deve ser educado numa visão ampla, proporcionando o desenvolvimento de suas faculdades intelectuais, através da experiência do educador, o que faz com que a cada ação de sua prática ocorra novas transformações.

Para isso, o artigo se divide em quatro partes. A Introdução, onde são apresentados o tema do estudo e sua fundamentação teórica. Em seguida, reflete-se sobre A educação nas relações do homem, partido das práticas dos antigos gregos e as percepções de experiência nos espaços de pensamento filosófico em seu berço cultural. A terceira seção, intitulada A experiência transforma $o$ ato educativo, trata sobre as abordagens conceituais de experiência dos autores propostos, apresentando um quadro teórico e desenvolvendo a percepção de evolução do conceito com o passar dos séculos. Por último, a Conclusão deste artigo permite a percepção do uso do conceito em diferentes tempos e espaços da história do homem e sua importância para a educação do homem.

\section{A EDUCAÇÃO NAS RELAÇÕES DO HOMEM}

As principais reflexões filosóficas dos pensadores gregos da Próton Filosofia (Pitágoras, Sócrates, Platão, Tales, Homero, Hesíodo, Heráclito, Zenão, Plotino) apresentam o conceito denso de significado, e a experiência sensível do homem reside em princípio divino (daimonion), unido a um corpo imortal. Contudo demonstrar o empenho categórico, que a tradição filosófica grega em seu bojo epistemológico dispensa em apresentar a interface da totalidade pedagógica a formação imprescindível e participação do homem em vida social e suas angustias existencial.

Acredita-se que os filósofos Homero e Hesíodo apresentam a celebração mítica da vida e a posição do homem em seu protagonismo no universo, através de um quadro 
cósmico, em cenário paradoxal de especulação cosmogônica, ampliando os discursos como este indivíduo se comporta bem como, estabelece suas tensões, fluxos, refluxos aos princípios da razão suficiente e o rigor metódico das causas primeiras e racional frente aos elementos poéticos e antropológicos.

De fato, estas especulações filosóficas consistem em imperativas ideias, e ganha corpo no pensamento de Tales de Mileto, que contempla, no exercício do logos e da razão, desmistificando a maneira pueril de compressão do mundo; a contemplação suprassensorial das ideias complexas e formais no cerne da questão que motiva a criticidade do aforismo filosófico em investigação incessante, a reflexão lógica do fundamento persuasivo e o crivo da consciência racional, além disso, assinala o reconhecimento da trajetória da consciência mítica e da reflexão filosófica.

A especulação filosófica da Paideia não admite, só e por si só, em seu bojo epistêmico, a transcendência da razão como verdade unívoca. Portanto, em suas práxis pedagógicas, contextualiza-se a experiência do homem atormentado em seus conflitos cotidianos de desigualdades sociais, econômicas e políticas, encontrando uma nova forma de denunciar a política e governança do Estado, que controla o poder, a administração e manutenção do bem-estar do homem, frente às tormentas da fome e miséria.

Neste contexto, a Pedagogia da Paideia não concorda com o sistema político e econômico que corrobora com a fome, injustiça e miséria que assolam e maltratam a sociedade oprimida pela escravidão, pavimentando, nesse sentido, os fundamentos da ordem social, como pressuposto basilar a garantir as condições sociais, econômicas e políticas que visam ampliar o desenvolvimento integral do homem.

Estas ideias celebradas à Paideia se aproximam do que é advogado nos dias atuais, através da Declaração dos Direitos do Homem e do Cidadão (criado 1789 em francês: Déclaration des Droits de e, Homme et du Citoyen), que é um documento culminante da Revolução Francesa, que busca difundir os direitos individuais e coletivos dos homens, como premissa universal e inequívoca a estabelecer justiça social e igualdade de direito, frente às representações econômicas, culturais e políticas.

O Artigo 2º desta Declaração Assevera a conservação dos direitos materiais imprescindíveis do Homem à liberdade, à propriedade, à segurança, à resistência e à 
opressão. Portanto, a aceitação sublime destas verdades afiança todos os cidadãos perante à lei e é estabelecido o aval e manutenção invioláveis e sagrados à manutenção máxima da sobrevivência e às condições igualitárias, tão caras em nossos dias.

Em comunhão com estas categorias de análise, Pitágoras, o gênio matemático, e Apolodoro, multiforme, dizem que os homens são felizes quando têm uma alma boa, mas ele não permanece sempre no mesmo estado de repouso, e nele, a situação não é sempre a mesma. Contudo, a vida humana é um constante devir em contínuas mudanças e, de acordo seus instintos passionais, tende para o bem e/ou para o mal. Assim, o homem, de acordo com a perspectiva pintada em tela, encontra equilíbrio e repouso para seu espírito, através das virtudes morais.

Nesta realidade do "vir a ser", Heráclito de Éfeso deixa um excepcional legado, ao tratar do fulcro do homem como resultado da experiência com o Logos, ou seja, a encruzilhada da existência humana depende incondicionalmente do conhecimento de si mesmo, só e por si só. O conhecimento do Logos capacita a consciência do homem adotar uma natureza reflexiva, compreendendo suas tensões do cotidiano ao ponto de, intuitivamente, torna-se capaz de suprimir suas angustias, exaltando o mérito da inefabilidade suprema das virtudes.

Na sequência, Heráclito de Éfeso exulta na atribuição do Logos, como via operativa ascendente, para chegar à verdade absoluta dos fatos. Essa ruptura epistemológica é fundante à compreensão do modelo ascendente da descoberta da verdade em uma crítica descendente aos prazeres. Esta dicotomia assinala uma ruptura radical, enquanto exprime a ideia potente do Logos e sua prevalência na transcendência da participação individual nos interesses da coletividade. Heráclito reforça o valor da transcendência, enquanto o homem aproxima o Logos sublime, em detrimento da contemplação cósmica transcendental.

$\mathrm{Na}$ antiguidade clássica, os ensinamentos de Platão, em A República, trouxeram excelentes contribuições que advogam a tessitura do cidadão da pólis, desde a formação do caráter à modelagem da vontade e, principalmente, da personalidade. Por meio do encadeamento, â educação compete a experiência prática de assoalhar as categorias e limitações do homem. 
A visão idealista de Platão identifica que, na natureza do homem da pólis, reside a possibilidade de desenvolver suas faculdades, estruturas e tecelagem intelectual cognitiva, um bem tão caro, pujante e capaz, até mesmo, de desmistificar o prazer do corpo e do espírito; tudo que é apócrifo à dimensão e manutenção da sobrevivência da vida humana.

Nesse sentido, Platão recomenda o aparelhamento estatal no plano do desenvolvimento da educação das crianças. De acordo com a visão dicotômica do plano natural e espiritual, o autor esquadrinha o homem como produto da soma das virtudes e sabedoria, ou seja, trata-se, de maneira especial, de uma visão burocrática e elitista, sobretudo, acessível a um grupo privilegiado, detentor do recurso econômico, passando a ser observado como mecanismo de manutenção do status que é, simbolicamente, da classe dos guerreiros, indivíduos fortes, e os magistrados de figura letrada.

Em consonância com a concepção de homem virtuoso, imbricado no espírito puro e casto, desponta Comenius, que propõe, em Didática Magna, a experiência de desvendar o método ideal em que professores, protagonistas do processo educativo, possam transmitir seus ensinamentos nas escolas, com proposta menos enfadonha e com alta produtividade, visando à expansão do reino de Deus e, prioritariamente, a moral cristã como instrumento devocional.

Segundo Comenius, há um encadeamento entre teoria e prática. $\mathrm{O}$ ensinamento conservador tem, na experiência do homem, os castigos físicos como forma de disciplinar os indivíduos, frente à educação progressista; perspectiva assumida como escopo na organização do sistema escolar, substanciando, em sua escola pansophica, o pavimento do saber virtuoso e a piedade cristã, que propagavam os ensinamentos de uma instrução sólida, alicerçada na economia do tempo

Comenius, em Didática Magna, esclarece, inicialmente, que a escola se assemelha a uma Catedral iluminada, um espaço de delícia e de atração, onde o homem se situa e experimenta o contato com o método, sistematizando o caminho para abrir a inteligência, exultando o mundo conveniente das boas ações ao saber efêmero e à experiência da vida, do sentido e da significação dos princípios constitucionais da natureza universal.

Em sequência, compreende-se que o método proposto por Comenius é um arranjo que traz, em sua envergadura, o aporte teórico do conceito a "A retê" (em grego, adaptação 
perfeita, excelência, virtude). De acordo com seus princípios, o homem era estimulado a alcançar a excelência física e moral, além da honra e da glória. Em sua vertente especulativa e hipotética, é de suma importância considerar a perspectiva dualística do corpo e da alma, bem como a complexidade imanente da vida, da relação e adaptação dos corpos em seu meio ambiente, com a tirania das sensações, matérias disformes e experiência dos corpos, e seu vir a ser no mundo da existência.

Para além de formar o homem, o método pedagógico proposto por Comenius designa uma exígua missão à educação, a de ensinar tudo a todos. A escola deve ainda aperfeiçoar o cidadão, deixando de ser suficiente, passando a simples e tradicional, com uma educação baseada na formação de transmissão de conhecimento, isto é, a formação intelectual; a significação da experiência de valores morais.

Quanto ao conceito de princípios universais, Comenius quebra os alicerces de uma educação burocrata, sistemática e indiferente às angústias e necessidades do homem, mas, antes de tudo, como por dignidade, uma educação sólida e portadora de um legado cultural incomensurável, distributiva, acessível a todos, sem distinção de cor, raça e classe, sem exploração econômica, igualitária e acessível, norteada nos princípios universais; algo revolucionário na história da educação, um processo desbravador na formação de excelência, agregando valor à experiência de todos os homens.

Baseado no entendimento da formação do homem, conferida pela educação, Rousseau (2004, p. 59) afirma que "Uma boa educação está em fazer um homem razoável: e pretende-se educar uma criança pela razão! É começar pelo fim, é querer fazer o instrumento com a obra”. Esse entendimento tem por objetivo suscitar e desenvolver na criança determinado número de estados físicos, intelectuais, morais e mentais, além de envolvê-lo e fomentar o uso da razão nos seus atos particulares.

Em consonância com o autor, é na formação educativa que as crianças necessitam compreender e acompanhar as transformações sociais, econômicas, intelectuais e evolutivas do seu ser; com ideias justas e claras. Sendo assim, a família, a sociedade e as instituições escolares precisam buscar ferramentas e recursos que possam contribuir com o homem em seu desenvolvimento cognitivo, intelectual e afetivo. 


\section{A EXPERIÊNCIA TRANSFORMA O ATO EDUCATIVO}

Ao debruçar-se nas leituras que envolvem pensamentos e reflexões, no que diz respeito ao entendimento do processo educacional, percebe-se que a experiência se destaca, enquanto conceito-chave, para compreender como os teóricos de diferentes períodos compreendiam a educação do homem.

Olhar para esse passado permite inferir que tais práticas que envolvem a experiência de quem ensinam e a experiência adquirida pelo alvo daquele processo podem contribuir para construir uma ideia de como o conceito se constitui na área da educação, e sua evolução ao longo dos séculos em que tais conceitos foram consolidando-se e participando diretamente da construção de uma ideia de educação.

O Quadro oI ${ }^{5}$ apresenta o conceito trabalhado por diferentes teóricos, em diferentes períodos da história do homem. Cada compreensão é própria do seu tempo, e pode dizer muito sobre o autor e a compreensão que a sociedade em que convivia tinha e como praticava a educação.

Quadro oI- Conceitos de Experiência ${ }^{6}$

\begin{tabular}{|l|l|l|l|}
\hline \multicolumn{1}{|c|}{ Autor } & \multicolumn{1}{|c|}{ Obra } & $\begin{array}{c}\text { Primeira } \\
\text { Publicação }\end{array}$ & \multicolumn{1}{c|}{ Contextualização } \\
\hline $\begin{array}{l}\text { Erasmo } \\
\text { Desiderius }\end{array}$ & $\begin{array}{l}\text { De civilitate } \\
\text { Morum } \\
\text { Puerilium }\end{array}$ & I530 & $\begin{array}{l}\text { "Engana-se, redondamente, quem julga } \\
\text { suficiente o fato de ter nascido. De não } \\
\text { menor erro padece quem crê adquirir } \\
\text { sabedoria só pelo trato das coisas e } \\
\text { gerência dos negócios sem as diretrizes da } \\
\text { filosofia. [...]. Não ficam fora da realidade } \\
\text { os antigos ao assegurar que expor se à } \\
\text { prova e tentar sucesso, exclusivamente, } \\
\text { mediante experiência, equivale a correr }\end{array}$ \\
\hline
\end{tabular}

\footnotetext{
${ }^{5}$ Neste cenário, encontra-se o conceito de experiência descrito na obra de John Dewey "Vida e Educação" e traduzido para o português por Anísio Teixeira. Na 5 $5^{\underline{a}}$ edição, de 1978, Teixeira é o tradutor é responsável por um estudo preliminar da obra de Dewey.

${ }^{6}$ Neste quadro, trabalha-se apenas com os autores que abordam, em suas obras, o conceito de experiência de forma direta, ou seja, conceituando o termo e refletindo sobre suas influências no processo educativo do homem. Por este motivo, Comenius não é abordado no quadro, pois suas reflexões são abordagens da ideia de experiência, no entanto, o autor não chega a conceituar o termo em sua obra.
} 


\begin{tabular}{|c|c|c|c|}
\hline & & & riscos" (p. 43-44). \\
\hline John Locke & $\begin{array}{l}\text { Ensaio acerca } \\
\text { do } \\
\text { entendimento } \\
\text { humano }\end{array}$ & I689 & $\begin{array}{l}\text { "Todo nosso conhecimento está nela } \\
\text { fundado, e dela deriva fundamentalmente } \\
\text { o próprio conhecimento" (p. } 57 \text { ). }\end{array}$ \\
\hline $\begin{array}{l}\text { Luiz Antônio } \\
\text { Verney }\end{array}$ & $\begin{array}{l}\text { Verdadeiro } \\
\text { Método de } \\
\text { Estudar }\end{array}$ & 1746 & $\begin{array}{l}\text { "O que digo é que este meio é o único para } \\
\text { descobrir a verdade: com esta } \\
\text { circunstância de mais que, ou nos descobre } \\
\text { a verdade, ou não nos lisonjeia, com uma } \\
\text { ciência mentirosa: pois nele claramente se } \\
\text { distingue, o que é verdadeiro, daquilo que } \\
\text { é verossímil, e que é falso" (p. } 36)\end{array}$ \\
\hline $\begin{array}{l}\text { Jean-Jacques } \\
\text { Rousseau }\end{array}$ & $\begin{array}{l}\text { Emílio ou Da } \\
\text { educação }\end{array}$ & 1762 & $\begin{array}{l}\text { "[...] é o verdadeiro estudo a que não nos } \\
\text { podem nunca aplicar cedo demais" (p. II4- } \\
\text { II5). }\end{array}$ \\
\hline $\begin{array}{l}\text { Herbert } \\
\text { Spencer }\end{array}$ & $\begin{array}{l}\text { Educação } \\
\text { Intelectual, } \\
\text { moral e physica }\end{array}$ & I86o & $\begin{array}{l}\text { "[...] por ela é que os homens abandonam } \\
\text { qualquer gênero de proceder mal ou tolo } \\
\text { que até então tenham adotado" (p. 2493- } \\
\text { 3968). }\end{array}$ \\
\hline $\begin{array}{l}\text { Anísio } \\
\text { Teixeira }\end{array}$ & $\begin{array}{l}\text { Vida } \\
\text { Educação }\end{array}$ & 1978 & $\begin{array}{l}\text { "Entendendo, porém, experiência como } \\
\text { um modo de existência da natureza, } \\
\text { vemos que ela é tão real quanto tudo que é } \\
\text { real" (p. } 14 \text { ). }\end{array}$ \\
\hline
\end{tabular}

Fonte: Quadro construído sob as perspectivas conceituais dos autores citados na referência deste artigo, 2020.

No século XVI, Erasmo Desiderius (1996) defendia que a natureza era de grande suficiência para ensinar ao homem como ele deveria ser e adquirir determinado conhecimentos para a sua sobrevivência. No entanto, é só a partir da educação que o homem consegue superar a natureza, ou seja, a partir do uso da razão aperfeiçoada, o hábito natural do homem de aprender pode ser desenvolvimento em sua plenitude.

Assim, o autor indaga que não é suficiente o fato de o homem ter nascido; é preciso correr riscos diante da natureza que lhe é imposta para, então, mediante a experiência, adquirir sabedoria de tratos filosóficos importantes para o amadurecimento do homem. Através dos estudos e do método, mediante a ensinamentos correlatos, o homem, 
enquanto animal racional, pode superar, através das experiências, as limitações da natureza.

Segundo as reflexões de Desiderius (1996), o estudo dos preceitos filosóficos e das experiências adquiridas em contato com a natureza, construía o conhecimento necessário para uma boa educação do homem. Tanto a filosofia quanto as experiências dos atos compõem a realidade, e dela, pode-se tirar toda sorte de conhecimentos.

O saber comportar-se na presença de adultos, do comer, do falar, do agir e do comportar-se eram preceitos com forte presença no período de Desiderius, e, para isso, a experiência tinha papel fundamental para a concretização desses conhecimentos.

Diferente da percepção de "superação da natureza", o iluminista inglês, John Locke (1983), defendeu, no século XVII, a ideia que todo o conhecimento deriva e estava fundamentado na experiência. Na percepção de Locke, a criança nasce como uma folha em branco, e, a partir da observação, pode construir ideias que derivam da sensação e da reflexão.

De acordo com os escritos deste autor, as sensações são as fontes das ideias, ou seja, percebe-se a ideia e, então, reflete-se sobre ela, transformando-a em conhecimento. Esse processo é intrínseco ao conceito de experiência abordado pelo autor, pois é a partir da experimentação que se consegue absorver sensações, refletir e construir ideias, isto é, possuir entendimento sobre um determinado objeto.

Outra separação interessante abordada por Locke (1983) é a diferença entre razão e experiência, que pode contribuir para a discussão. Razão, para ele, pode ser entendida como a capacidade de deduzir, criar hipóteses; verdades desconhecidas de princípios já conhecidos, ou seja, é refletir e supor diante de conhecimentos já firmados e conseguir gerar novas discussões. Já a experiência, vai avançar quando permite que se experimente o conhecimento e descubra que outras qualidades coexistem no campo da ideia. Desta forma, “[...] a experiência deve aqui me ensinar o que a razão não pode” (LOCKE, 1983, p. 28I).

O que o autor chama de "razão", ao avançar para o século XVIII, o iluminista português, Luís Antônio Verney (1952), vai chamar de "experiência". Neste ponto, o pensador lusitano defende que a experiência é o único meio de encontrar a verdade. Fora da experiência, só se pode encontrar uma "ciência mentirosa", ou seja, apenas com a 
experiência, é possível aproximar-se do que é verossímil com a verdade. Neste ponto, Verney (1952) vai relatar que razão e verdade são "uma coisa só", ambas adquiridas por meio da experiência.

Contemporâneo a Verney, Rousseau, em 1762, publica a primeira versão do Emílio. Correlacionado a experiência, o pensador acredita que só é possível compreender o uso dos órgãos humanos através do exercício, do seu uso cotidiano, por experiência adquirida por meio do uso contínuo dos membros (mãos, braços, pernas, cabeça etc.). No entanto, defende também que experiência é algo que nunca deve ser aplicada cedo demais.

Em contradição a seu tempo, Rousseau pensava que a criança não é um modelo de adulto que deve ser ensinado a agir como tal, muito menos adquirir as experiências das mesmas formas que um homem adulto obtém. Em suas reflexões, definia que a educação tinha origem em três faculdades; Natureza, Homem e Objetos.

Para ele, obtém-se o desenvolvimento das habilidades e do corpo por meio da natureza. O que se faz com esse desenvolvimento e como essa relação ocorre com o entorno, é de responsabilidade do homem. Já a construção das experiências sobre os objetos que afetam, direta e indiretamente, era a educação das coisas, dos objetos (ROUSSEAU, 2004).

Entende-se, então, que o modelo de educação de Rousseau está baseado em uma triangulação, que, por sua vez, é fundamentada na Natureza, no Homem e nos Objetos. Desta forma, percebe-se que a experiência possui importância significativa, no entanto, não deve ser empregada na educação das crianças cedo demais. A educação, por meio da natureza e do homem, deve agir em primeira instância, para, somente depois, a experiência ser construída a partir da relação com a natureza e os objetos por meio da educação dada pelo homem.

Logo depois, no século XIX, a experiência já é vista sob uma perspectiva diferente, na ótica de Herbert Spencer. Para o autor, a experiência seria a chave para que o homem não agisse de forma ou gênero que possa ser interpretado como mal, ou que sejam atitudes tolas, indignas de um homem culto e bem-educado. E mesmo que as circunstâncias agissem para atos maldosos, a experiência iria garantir ao homem que refletisse sobre seus atos e não desse prosseguimento às suas atitudes danosas. 
Percebe-se, então, que, desta forma, Spencer (s/d) entende a educação enquanto um processo moralizador, pois sua conceituação de experiência indica que ela serve para guiar o homem em suas atitudes. Assim, a experiência, em sua compreensão, é reguladora das atitudes do homem, pois é quem demonstra e permite que o homem saiba quando sua atitude pode ser mal ou imprópria para sua conduta.

Spencer $(\mathrm{s} / \mathrm{d})$ também indaga que a experiência precisa ser refletida. A prática precisa caminhar para o empírico, passar pelo campo racional. Tal concepção está ligada à ideia da educação e experiência enquanto atos regulatórios da moralidade. Desta forma, a natureza, por si só, pode educar e punir a criança, quando ela mesma, por suas ações, adquire experiências e reflete sobre tais ações, tendo o adulto apenas como mediador destes processos.

Chegando ao século $\mathrm{XX}$, o conceito que se vai tratar aqui não é o diretamente pensado por Dewey, mas, sim, por Anísio Teixeira. Na obra Vida e Educação, edição de 1978, Teixeira propõe um esboço da teoria educacional de Dewey e proporciona reflexões interessantes sobre as perspectivas de experiência que fazem parte do processo educativo da criança e do homem.

Para Teixeira (1978), convive-se em um ambiente com infinitos elementos que se relacionam cotidianamente. Estas relações promovem trocas e influenciam diretamente no modo em que é construída a maneira de intervir no mundo, e obriga a uma eterna transformação dos corpos, das mentes e dos gestos.

Este processo passa por duas etapas, reflexão e reconstrução. A reflexão está ligada ao agir e reagir diante das atividades cotidianas, ou seja, as relações com o outro e com os objetos que compõem a realidade; transforma a maneira de agir e reagir. Após tal reflexão, a experiência passa por uma reconstrução, onde o homem se remodela a partir das experiências criadas diante das relações e reflexões construídas diariamente.

Assim, Teixeira (1968) defende que "A experiência é um modo de existência da natureza [...]. [...] vemos que ela é tão real quanto tudo que é real” (p. I4). A experiência é tão concreta, que sua transformação altera a própria realidade dos sujeitos que se relacionam e constroem suas experiências. Desta forma, percebe-se que a experiência não é um elemento cognitivo em si, no entanto, com a transformação das relações em 
experiência, pode ganhar o atributo de cognição, “[...] que será tão real e orgânico, quanto qualquer dos outros que já possua” (TEIXEIRA, 968, p. I4).

Outra característica importante é a reflexão que Teixeira proporciona sobre as experiências nas primeiras idades. Diferente de Rousseau (2004), que acredita que as fases experimentais com objetos e natureza nunca deveriam ser empregadas cedo demais na criança; Teixeira (1978), na obra de Dewey, apresenta a reflexão de que a criança, logo ao nascer, já começa a experimentar sentimentos e sensações, mesmo antes de ter as experiências concretizadas ou de, ao menos, saber o que significa tudo que sente e experimenta. Em sua concepção, essas são experiências, diferente de um segundo e terceiro tipos de experiências.

Em uma segunda concepção, a experiência proporciona reflexões que podem gerar conhecimento sobre determinado fato experimentado, desde que haja uma reflexão consciente do fato experimentado. No terceiro tipo, Teixeira afirma que deriva dos sentimentos vagos que o homem possui, o qual não se sabe ao certo o que é, mas que se sente ou se advinha.

Apresentando tais conceitos, percebe-se que não há como comparar os conceitos em seus diretos tempos e espaços de concepção. Cada pensador tem uma proposta diferente, que respondia aos anseios do seu tempo e da sua sociedade. Quando Desiderius (1996) pensou a experiência, refletiu sobre a sociedade em que a educação era apenas para meninos que pertenciam a famílias abastadas e que tinham condições financeiras para investir na educação do seu filho. Já Locke (1983), no século seguinte, traz a experiência dentro do pensamento empírico, dando outro tratamento ao conceito.

Enquanto Desiderius (1996) defende que o conhecimento é adquirido por meio da filosofia e das experiências que ajudam a superar as limitações da natureza, Locke (1983) vai defender que a experiência é o próprio conhecimento, estando completamente fundado nela. A base empírica do raciocínio deste autor permite aferir que o conhecimento é todo construído a partir das relações criadas com os objetos e reflexões de ideias sensíveis e reflexivas.

Ainda segundo Locke (1983), pode-se perceber que a base empírica vai ser importante para pensar o papel da experiência no ato de educar o homem. Rosseau (2004), 
no entanto, difere, quando defende que o conceito não deve ser implantado tão cedo na criança, e que tais atos devem ser abordados com idade mais avançada. Não obstante, Verney (1952), Spencer (s/d) e Teixeira (1978) defendem que o conceito é chave para que o processo educacional seja significativo, e que a criança aprenda por meio das relações experimentais que a natureza e o cotidiano oferecem.

É interessante salientar a importância de pensar sobre a evolução do conceito com o passar dos séculos e das reflexões dos pensadores da filosofia e da educação. Teixeira (1978) vai chamar todas essas experiências de "Experiências Humanas". Nesse prisma, vale complementar dizendo que são "[...] acumulações muitas vezes seculares de tudo que o homem sofreu, conheceu e amor" (TEIXEIRA, 1978, p. 15).

Tal afirmação só demonstra o quanto o conceito perpassou, por muito tempo, as ideias e reflexões no ato educativo do homem, pois essa experiência se nutre de materiais e direciona as atuais experiências. Assim, a própria vida é um laboratório experiencial, onde as relações são inovadas, refletidas e sentidas, transformadas em conhecimentos próprios para cada indivíduo, e importância que atribui, ao ato de experimentar, uma ação.

Deste modo, atribui-se importância à experiência, enquanto ato transformador e que outorga movimento na construção do conhecimento e de novas abordagens e métodos à ciência da educação. Pensar a experiência entre os tempos e pensadores, permite inferir a evolução de abordagem do conceito e como este auxilia nas meditações para aprimoramento do processo educativo do homem.

\section{CONCLUSÃO}

Este artigo teve como proposta tratar da evolução do conceito de experiência entre os séculos XVI e XX da era cristã, abordando as reflexões de diferentes pensadores da filosofia e da educação. Para cuidar do objetivo principal do texto, iniciou-se a reflexão acerca da relação do homem com a educação, partindo do ponto da história em que o homem percebe que a experiência é fundamental para o processo de educação do sujeito.

Percebeu-se que, desde os tempos da antiga Grécia, o homem refletia em como suas experiências poderiam ser impactantes no ato de aprender, em outros termos, no ato educacional. A experiência demonstra ser um conceito importante para que se possa 
compreender a evolução só do seu conceito em si, mas também das práticas de educação e de quem tinha acesso a ela.

É notório também que a presença do cosmos divino, no pensamento pedagógico, é quase que unânime entre os pensadores. Por mais que alguns defendam uma educação escolar laica, o divino possui um importante espaço nas experiências educativas da criança e do homem. Em algumas triangulações desses pensamentos, há sempre um espaço para Deus, Natureza e Homem. Um conjunto inseparável das práxis cotidianas de quem era alvo da educação e do processo de moralidade e ética.

Não há como comparar, e não foi intenção deste texto, as diferentes concepções e conceituações de experiência que os pensadores apresentam. Mas, é perceptível que ocorre uma evolução no conceito, por mais que haja semelhanças. Após Locke (1983), o empirismo ganha espaço significativo nas reflexões sobre a importância da experiência no momento da educação. Teixeira (1978), na obra de Dewey, assevera que o empirismo possui espaço em suas reflexões, mas nota-se também a evolução que o conceito ganha.

Desta forma, conclui-se que as "experiências humanas", mesmo que só apresentadas desta forma por Teixeira, foi objeto de reflexão entre antigos gregos e escolásticos, mas que ganha mais força e forma entre os modernos e contemporâneos; tempo em que a educação começa a ampliar seus espaços de atuação e passa por processo de reestruturação e pensamento sobre as necessidades intelectuais e empíricas que o homem necessita ter para uma boa educação. Portanto, é notória a importância que a experiência possui, assim como se percebe o quanto é imprescindível nas relações do homem com a ideia de saberes e conhecimento.

\section{REFERÊNCIAS}

COMENIUS, Iohannis Amos. Didática Magna. Disponível em: <https://ww2.nifap.r/ dfisica/files/2014/12/A_didactica_magna_COMENIUS.pdf $>$. Acesso em 29 Mar. 2020.

DESIDERIUS, Erasmo. De Civilitate Morum Puerilium. Valencia: Universidad Valencia, 1996.

DEWEY, John. Vida e Educação. São Paulo: Edições Melhoramentos, 1978. 
FROEBEL, Friedrich. A Educação do homem. Passo Fundo: Editora da Universidade de Passo Fundo, 20or.

LOCKE, John. Ensaio acerca do entendimento humano. São Paulo: Abril Cultural, 1983. (Coleção Pensadores).

PESTALOZZI, Johann H. Carta sobre Educacion infantil. Madri: Tecnos, 2000.

ROUSSEAU, Jean-Jacques. Emílio ou Da Educação. São Paulo, Martins Fontes, 2004.

SPENCER, Herbert. Educação intelectual, moral e physica. Porto: Livraria Moderna, s/d.

VERNEY, Luiz Antônio. Verdadeiro método de estudar. Lisboa: Oficina Gráfica Ltda, 1952. 